\title{
Growth Pattern in Children with Juvenile Idiopathic Arthritis: A Retrospective Study
}

\author{
Rana A. Alsulami', Ahlam 0. Alsulami' ${ }^{1}$, Mohammed A. Muzaffer ${ }^{2}$ \\ ${ }^{1}$ King Abdulaziz University, Jeddah, Kingdom of Saudi Arabia \\ ${ }^{2}$ Department of Pediatric, King Abdulaziz University Hospital, Jeddah, Kingdom of Saudi Arabia \\ Email: mmuzaffer@hotmail.com
}

How to cite this paper: Alsulami, R.A., Alsulami, A.O. and Muzaffer, M.A. (2017) Growth Pattern in Children with Juvenile Idiopathic Arthritis: A Retrospective Study. Open Journal of Rheumatology and Autoimmune Diseases, 7, 80-95.

https://doi.org/10.4236/ojra.2017.71007

Received: December 12, 2016

Accepted: February 11, 2017

Published: February 14, 2017

Copyright (c) 2017 by authors and Scientific Research Publishing Inc. This work is licensed under the Creative Commons Attribution International License (CC BY 4.0).

http://creativecommons.org/licenses/by/4.0/

\begin{abstract}
Aim of this study is to assess growth pattern in children with juvenile idiopathic arthritis (JIA) and factors associated with growth retardation. Methods: A retrospective chart review of all cases of JIA following up at Pediatric Department of King Abdulaziz University Hospital, between July 2000 to July 2016. Demographic, clinical and biological data were collected and analyzed as risk factor for growth retardation. These included age, gender, age at diagnosis, disease duration, type of JIA, the presence of uveitis, rheumatoid factor (RF) positivity, antinuclear antibody (ANA) titer and treatment. Growth pattern was assessed as the percentile for height-for-age, weight-for-age and weight-for-height in reference to the Growth Chart for Saudi Children and Adolescents. Change in percentile rank was divided into 3 categories: regression (a drop of $\geq 1$ percentile); stable (uphold of the same percentile); and progression (change for a superior percentile). Results: A total 78 children were eligible, $52.6 \%$ females, mean \pm SD age $=9.94 \pm 4.92$ years, and age at diagnosis $=7.44 \pm 4.52$ years, mean $\pm \mathrm{SD}$ [range] disease duration $=2.93 \pm$ 2.70 [6 months; 15 years]. The most frequent types of JIA were systemic (33.3\%), oligoarticular (30.8\%) and polyarticular negative RF (26.9\%). Other parameters included positive ANA in $41.0 \%$, positive RF in $7.7 \%$ and uveitis in $9.0 \%$. The most frequent treatment was methotrexate (59.0\%), followed by biological therapy $(47.4 \%)$, non-steroid anti-inflammatory drugs (43.6\%) and prednisolone (33.3\%). Growth data were available for 67 (85.9\%) children, and assessments showed $36 \%$ cases of break of the growth curve in both height-for-age and weight-for-age percentiles and $31 \%$ in weight-for-height percentiles. In all three parameters, there were shifts towards lower percentiles from time of diagnosis to last follow-up, in both males and females. Correlation and regression analysis showed low age at diagnosis and disease duration to be significant predictors for growth retardation severity. Conclusion: One in three children with JIA has growth retardation, the severity of which is predicted by low age at disease onset and long disease duration.
\end{abstract}




\section{Keywords}

Juvenile Idiopathic Arthritis, Growth Pattern

\section{Introduction}

Juvenile idiopathic arthritis is a heterogeneous group of inflammatory diseases characterized by chronic arthritis with various clinical presentations [1]. Although genetic and environmental factors have been identified, the origin and pathophysiology of the disease are not well elucidated [1]. It is considered to be one of the most frequent chronic diseases in pediatric patients; its prevalence ranges from 3.8 to 400 per 100,000 with frequently reported female predominance [2] [3] [4]. In the United States, it is estimated that 250,000 children are affected with juvenile idiopathic arthritis [5].

The International League of Associations for Rheumatology (ILAR) classified JIA into 7 sub-types according to the degree and extent of arthritis and biological markers [6]. Besides having different clinical features, each sub-type has a particular prognosis profile and response to the different therapies [7]. In Saudi Arabia, the most common sub-types of JIA are systemic onset and oligoarticular forms [8].

The disease course is characterized by successive flare-ups with more or less disease activity and generally short-remissions [9]. There are various therapeutic approaches in JIA, aiming generally to reduce the number of flare-ups and inflammatory activity, relieve pain and limit the progression of the disease [10]. Steroids and non-steroid anti-inflammatory drugs (NSAIDs) have been for many years the main pharmacological resource; and methotrexate and antitumor necrosis factor (anti-TNF- $\alpha$ ) such as etanercept and infliximab have been introduced later, all having a limited efficacy and considerable adverse effects. More recently, anti-interleukin 6 (anti-IL-6) therapies such as tocilizumab and anti-IL-1 therapies have demonstrated better results, especially in systemic-onset JIA [11]. It is crucial to diagnose and treat JIA early to prevent irreversible joint damage and soft-tissue deformities; which are more frequent and sever in polyvarticular form with positive rheumatoid arthritis [12] [13]. Number of other complications are reported with uveitis being the most frequent extra-articular characterized with severs outcomes, such as glaucoma, cataract and irreversible vision loss [7] [14] [15].

Growth impairment is a frequent complication of JIA found in $35 \%$ to $40 \%$ of the afflicted children [16] [17]. It can have generalized form causing short body stature [18], or may interest the affected limb exclusively [9]. Growth disorders are associated with long-term disability, which impacts the patient's and family quality of life and represents substantial economic burden [19]. Like other JIA complications, growth disorder are function of disease duration and activity, with more severe cases observed in patients with high, long-term inflammatory profiles, such as systemic and polyarticular JIA sub-types [7] [20]. Other associated risk factors 
such as low age of onset and long-term use of corticoids may significantly contribute in severity of growth retardation [17] [21]. Therefore, assessing growth pattern in children and adolescents with JIA is a crucial indicator of disease activity and therapeutic success. It should be systematically used as a complement for treatment efficacy assessment. Furthermore, there is lack of data in the Middle-Eastern region regarding growth patterns and growth impairment among JIA children. We conducted this study to explore growth pattern among children afflicted with JIA in Saudi Arabia; and to assess prevalence and risk factors of growth retardation.

\section{Methods}

A retrospective chart review was carried out on all children (aged $<20$ years) following up for JIA at the Pediatric Department of King Abdulaziz University Hospital, Jeddah, Saudi Arabia, between July 2000 to July 2016.

All cases were diagnosed according to the International League of Associations for Rheumatology (ILAR) criteria for JIA based on onset age $<16$ years, 6-week or more disease duration, and with exclusion of other conditions [6] [22]. Type of JIA (systemic, oligoarticular, extended oligoarticular, polyarticular with negative rheumatoid factor (RF), polyarticular with positive RF, psoriatic, enthesitis-related arthritis and undifferentiated arthritis) was determined according to ILAR classification for JIA [6] [22] [23].

Classification of weight and height was done using the Growth Charts for Saudi Children and Adolescents (endorsed by The Health Services Council of Saudi Arabia No.29, 24/6/2007) [24]. Growth pattern was assessed as the change in percentile rank for height-for-age, weight-for-age and weight-for-height, from time of diagnosis (T0) to last follow-up (T1). Change in percentile rank was divided into 3 categories: regression (a drop of $\geq 1$ percentile); stable (uphold of the same percentile); and progression (change for a superior percentile).

Demographic, clinical and biological data were collected and analyzed as risk factor for growth retardation. These included age, gender, age at diagnosis, disease duration, type of JIA (systemic, polyarticular RF-, polyarticular RF+, oligoarticular and extended oligoarticular), presence of uveitis, rheumatoid factor (RF) positivity, antinuclear antibody (ANA) titer and treatments used (NSAIDs, methotrexate, prednisolone, and biological treatments).

\section{Statistical Methods}

Statistical analysis was performed with the Statistical Package for Social Sciences Version 21.0.0.0 for Windows (SPSS Inc., Chicago, IL, USA, 2012). Categorical variables are presented as frequency and percentage, while continuous variables are presented as mean \pm standard deviation (SD). Growth pattern was classified as regression, stable or progression according to loss, maintain or win in percentile rank from diagnosis time to last follow-up, respectively. Analysis of growth impairment-associated risk factors was done using two categories: regression/no regression. Correlations of growth patterns and growth impairment with demo- 
graphic and clinical factors were analyzed using chi-square test in categorical variables, and independent $t$-test or One-Way Analysis of Variance (ANOVA) in continuous variables, as appropriate. Analysis of the severity of growth impairment indicated by the number of percentile ranks lost from diagnosis time to last follow-up was carried out using univariate and multivariate ordinal regression models; results were presented in scatter plots and fit curve, with calculation of odds-ratios and $95 \% \mathrm{CI}$. A p value of $<0.05$ was considered to reject the null hypothesis.

\section{Results}

\subsection{Patients' Characteristics}

A total 78 children with JIA were eligible for the study, $52.6 \%$ females, mean \pm SD age $=9.94 \pm 4.92$ years, and age at diagnosis $=7.44 \pm 4.52$ years. They were followed up for a mean $\pm \mathrm{SD}$ [range] disease duration $=2.93 \pm 2.70$ [6 months; 15 years]. The most frequent types of JIA were systemic (33.3\%), oligoarticular (30.8\%) and polyarticular negative RF (26.9\%). Other parameters included positive ANA in $41.0 \%$, positive RF in $7.7 \%$ and uveitis in $9.0 \%$. The most frequent treatment was methotrexate (64.1\%), followed by biological therapy $(47.4 \%)$ (Table 1).

Table 1. Demographic and clinical characteristics of children with juvenile idiopathic arthritis.

\begin{tabular}{|c|c|c|c|}
\hline Parameter & Value & Frequency/mean & Percentage/SD \\
\hline Age & Range $=9$ months; 20.00 years & 9.94 & 4.92 \\
\hline \multirow{2}{*}{ Gender } & Male & 37 & 47.4 \\
\hline & Female & 41 & 52.6 \\
\hline Age at diagnosis & Range $=6$ months; 16.00 years & 7.44 & 4.52 \\
\hline Weight at diagnosis & Range $=6.60 ; 63.00 \mathrm{Kg}$ & 28.85 & 16.44 \\
\hline Height at diagnosis & Range $=63 ; 167 \mathrm{~cm}$ & 119.76 & 27.23 \\
\hline Disease duration & Range $=2$ months; 15.00 years & 2.93 & 2.70 \\
\hline \multirow{5}{*}{ Diagnosis } & Systemic & 26 & 33.3 \\
\hline & Polyarticular RF+ & 5 & 6.4 \\
\hline & Polyarticular RF- & 21 & 26.9 \\
\hline & Oligoarticular & 24 & 30.8 \\
\hline & Extended Oligoarticular & 2 & 2.6 \\
\hline \multirow{4}{*}{ Treatment } & NSAIDs & 34 & 43.6 \\
\hline & Methotrexate & 50 & 64.1 \\
\hline & Prednisolone & 26 & 33.3 \\
\hline & Biological & 37 & 47.4 \\
\hline \multirow{4}{*}{ ANA } & Negative $(<1: 40)$ & 46 & 59.0 \\
\hline & Mild positive (1:40 - 1:160) & 22 & 28.2 \\
\hline & Moderately positive (1:320 - 1:640) & 6 & 7.7 \\
\hline & Strongly positive $(>1: 640)$ & 4 & 5.1 \\
\hline \multirow{2}{*}{ Rheumatoid Factor } & Negative & 72 & 92.3 \\
\hline & Positive & 6 & 7.7 \\
\hline Uveitis & & 7 & 9.0 \\
\hline
\end{tabular}

SD: Standard deviation; RF+: positive rheumatoid factor; RF-: negative rheumatoid factor; NSAIDs: non-steroid anti-inflammatory drugs; ANA: antinuclear antibody. 


\subsection{Growth Parameters}

Growth data were available for 67 (85.9\%) children only. Analysis of weight, height and weight-for-height percentiles showed $46.2 \%, 46.2 \%$ and $39.7 \%$ breaks of the respective growth curves between time of diagnosis and last follow-up (Table 2). In all three growth parameters there were shifts towards lower percentiles from time of diagnosis to last follow-up, which was observed in both genders (Figures 1-3).

Table 2. Growth parameters of children with juvenile idiopathic arthritis.

\begin{tabular}{|c|c|c|c|}
\hline Parameter & Value & Frequency/Mean & Percentage/SD \\
\hline \multicolumn{4}{|l|}{ Weight } \\
\hline At diagnosis & Mean, SD (Kg) & 28.85 & 16.44 \\
\hline \multirow[t]{2}{*}{ At last follow-up } & Mean, SD (Kg) & 37.14 & 23.81 \\
\hline & Regression & 36 & 46.2 \\
\hline \multirow[t]{2}{*}{ Growth pattern ${ }^{1}$} & Stable & 20 & 25.6 \\
\hline & Progression & 11 & 14.1 \\
\hline \multicolumn{4}{|l|}{ Height } \\
\hline At diagnosis & Mean, SD (cm) & 119.76 & 27.23 \\
\hline \multirow[t]{2}{*}{ At last follow-up } & Mean, SD $(\mathrm{cm})$ & 166.50 & 129.27 \\
\hline & Regression & 36 & 46.2 \\
\hline \multirow[t]{2}{*}{ Growth pattern ${ }^{1}$} & Stable & 16 & 20.5 \\
\hline & Progression & 15 & 19.2 \\
\hline \multicolumn{4}{|l|}{ Weight-for-height } \\
\hline & Regression & 31 & 39.7 \\
\hline \multirow[t]{2}{*}{ Growth pattern ${ }^{1}$} & Stable & 21 & 26.9 \\
\hline & Progression & 16 & 20.5 \\
\hline
\end{tabular}

${ }^{1}$ Growth pattern was assessed according to the change in percentile rank from time of diagnosis to last follow-up, which was classified into 3 categories: regression $=$ drop to a lower percentile; stable $=$ maintaining the same percentile; progression $=$ change to a superior percentile .

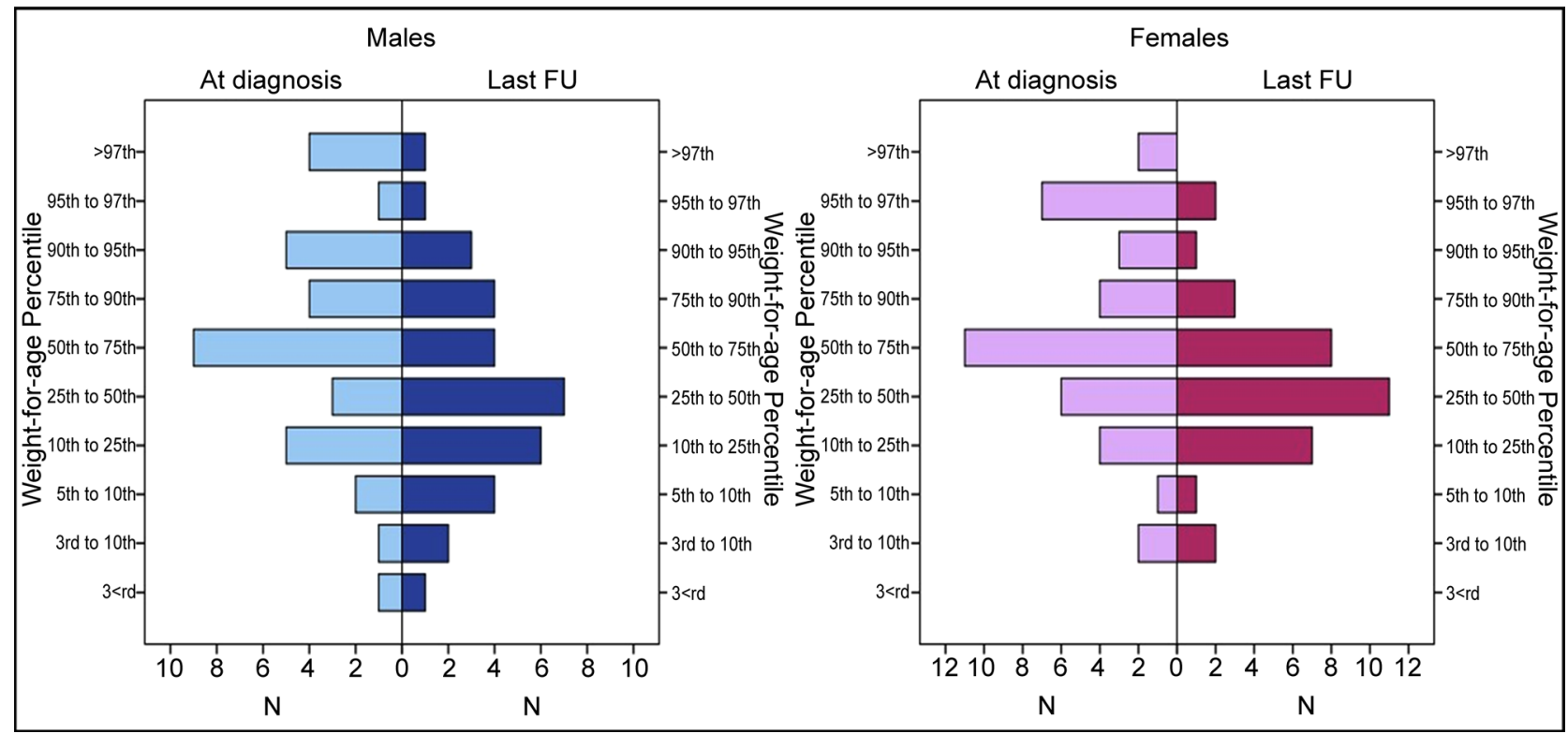

Figure 1. Weight-for-age percentiles in male and female children with juvenile idiopathic arthritis, at diagnosis and at last followup visit (median [range] follow-up duration $=2.00[0.20-13.00]$ years in males and $3.00[0.50-12.00]$ years in females; $\mathrm{p}=0.086$ Mann-Whitney U test). 


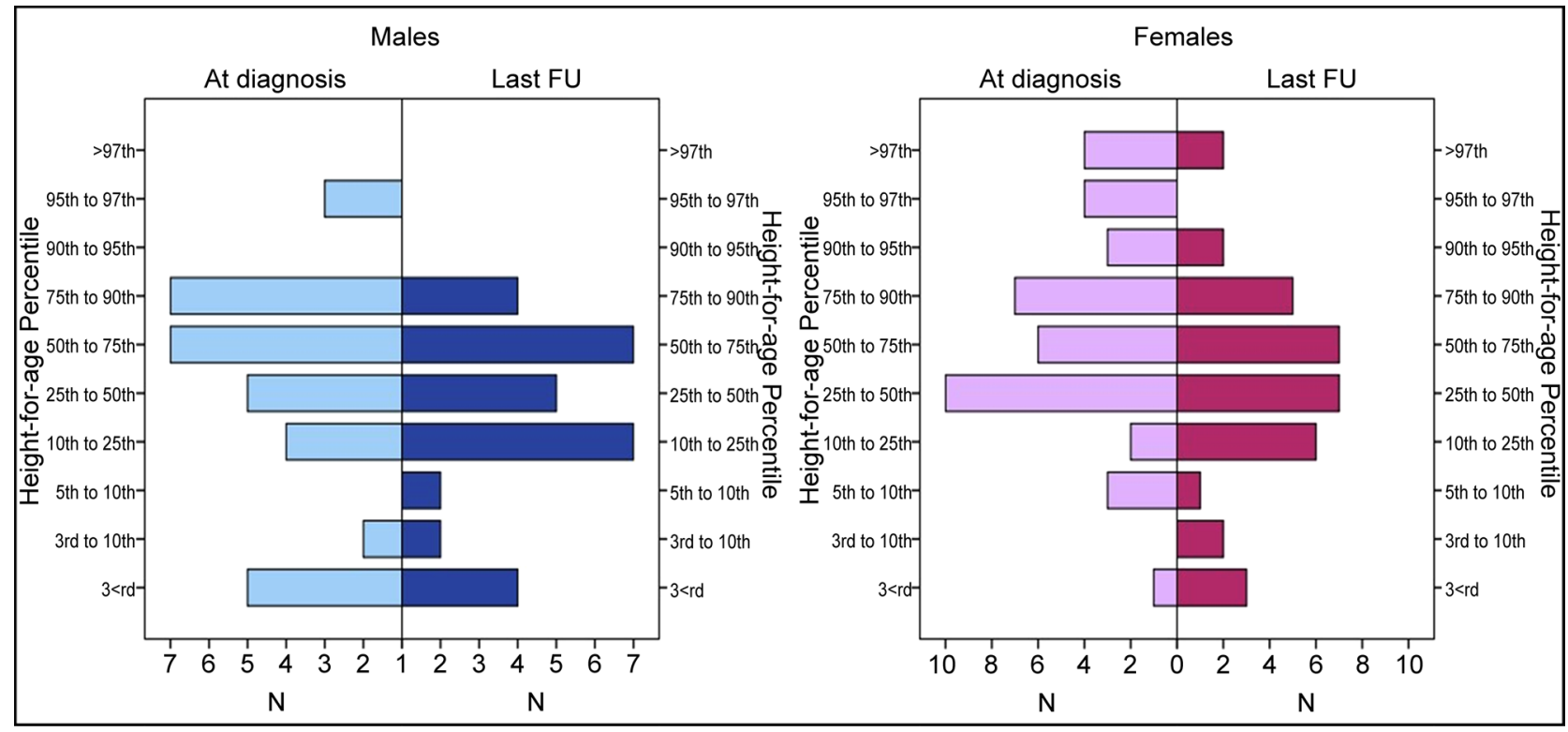

Figure 2. Height-for-age percentiles in male and female children with juvenile idiopathic arthritis, at diagnosis and at last followup visit (median [range] follow-up duration $=2.00[0.20-13.00]$ years in males and $3.00[0.50-12.00]$ years in females; $p=0.086$ Mann-Whitney U test).

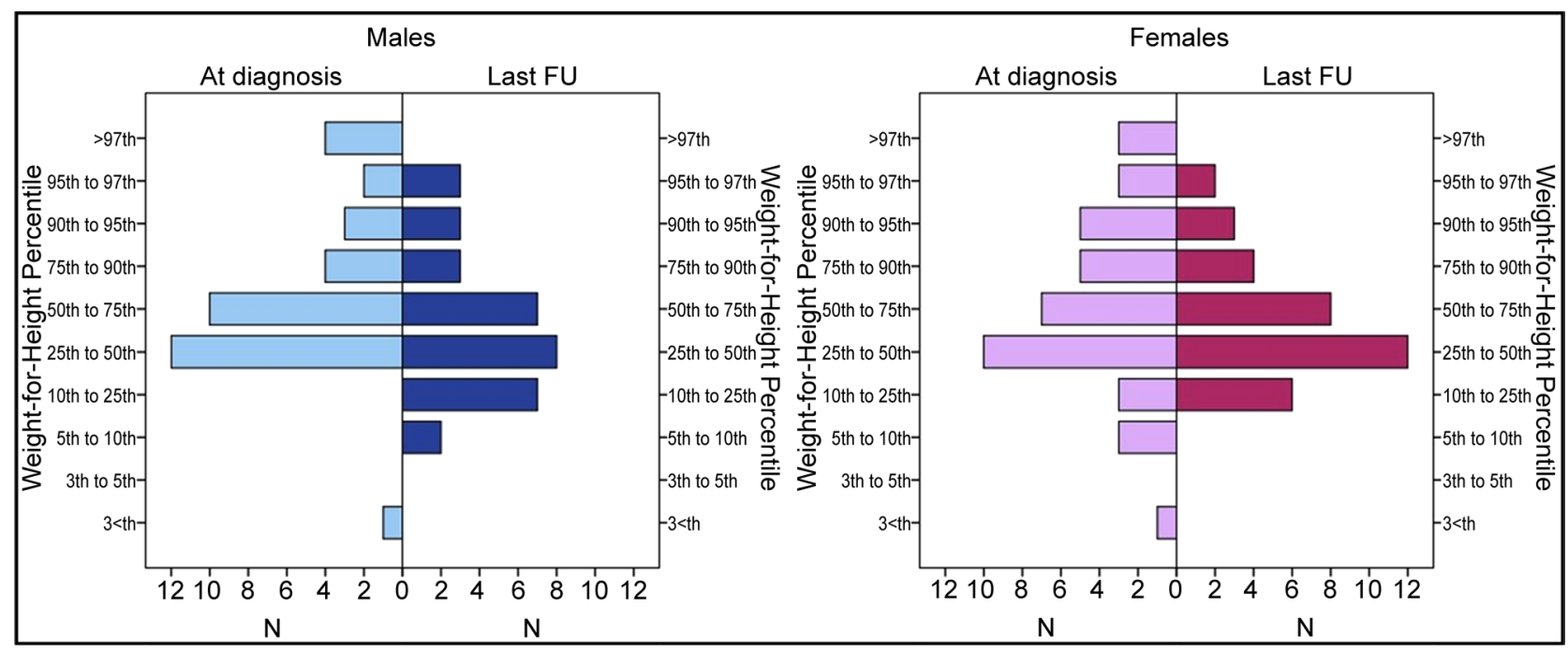

Figure 3. Weight-for-height percentiles in male and female children with juvenile idiopathic arthritis, at diagnosis and at last follow-up visit (median [range] follow-up duration $=2.00[0.20-13.00]$ years in males and $3.00[0.50-12.00]$ years in females; $\mathrm{p}=$ 0.086 Mann-Whitney U test).

\subsection{Demographic and Clinical Factors Correlated with Growth Impairment}

Correlation of height-for-age growth curve with demographic and clinical factors showed that children who regressed in the percentile rank from T0 to T1 had lower age at diagnosis than those who did not regress (mean \pm SD age $=$ $6.69 \pm 4.02$ versus $8.54 \pm 4.88$ years, respectively; $p=0.093$ ) and longer disease duration ( $3.31 \pm 2.21$ versus $1.97 \pm 1.28$ years; $\mathrm{p}=0.004$, respectively). Analysis of the other factors, such as gender, JIA sub-type, treatment or biological data showed no significant difference between the two groups. 
Regarding weight-for-age, children who regressed had longer disease duration than those who did not regress $(3.20 \pm 2.10$ versus $2.10 \pm 1.57$ years; $p=0.020$, respectively). No difference was observed in other factors; except a higher proportion of prednisolone use among children who had growth retardation versus who had normal growth (68.0\% versus $32.0 \%)$, however, this result was not statistically significant $(\mathrm{p}=0.071)$ (Table 3$)$.

Table 3. Demographic and clinical factors correlated with break of the growth curve (regression) among children with JIA.

\begin{tabular}{|c|c|c|c|c|c|c|c|c|c|c|}
\hline \multirow{3}{*}{ Parameter/Value } & \multicolumn{5}{|c|}{ Height-for-age } & \multicolumn{5}{|c|}{ Weight-for-age } \\
\hline & \multicolumn{2}{|c|}{ Regression } & \multicolumn{2}{|c|}{ No regression } & \multirow{2}{*}{$\mathrm{p}$-value } & \multicolumn{2}{|c|}{ Regression } & \multicolumn{2}{|c|}{ No regression } & \multirow{2}{*}{ p-value } \\
\hline & Freq. & $\%$ & Freq. & $\%$ & & Freq. & $\%$ & Freq. & $\%$ & \\
\hline \multicolumn{11}{|l|}{ Gender } \\
\hline Male & 16 & 50.0 & 16 & 50.0 & \multirow{2}{*}{0.558} & 19 & 59.4 & 13 & 40.6 & \multirow{2}{*}{0.376} \\
\hline Female & 20 & 57.1 & 15 & 42.9 & & 17 & 48.6 & 18 & 51.4 & \\
\hline Age at diagnosis (mean, SD; years) & 6.69 & 4.02 & 8.54 & 4.88 & $0.093^{*}$ & 7.01 & 4.15 & 8.17 & 4.88 & 0.298 \\
\hline Disease duration (mean, SD; years) & 3.31 & 2.21 & 1.97 & 1.28 & $0.004^{\star}$ & 3.20 & 2.10 & 2.10 & 1.57 & $0.020^{*}$ \\
\hline \multicolumn{11}{|l|}{ Diagnosis } \\
\hline Systemic & 13 & 52.0 & 12 & 48.0 & \multirow{5}{*}{0.529} & 12 & 48.0 & 13 & 52.0 & \multirow{5}{*}{0.331} \\
\hline Polyarticular RF+ & 1 & 20.0 & 4 & 80.0 & & 1 & 20.0 & 4 & 80.0 & \\
\hline Polyarticular RF- & 11 & 64.7 & 6 & 35.3 & & 12 & 70.6 & 5 & 29.4 & \\
\hline Oligoarticular & 10 & 55.6 & 8 & 44.4 & & 10 & 55.6 & 8 & 44.4 & \\
\hline Exd. oligoarticular & 1 & 50.0 & 1 & 50.0 & & 1 & 50.0 & 1 & 50.0 & \\
\hline \multicolumn{11}{|l|}{ NSAIDs } \\
\hline No & 19 & 48.7 & 20 & 51.3 & \multirow{2}{*}{0.331} & 21 & 53.8 & 18 & 46.2 & \multirow{2}{*}{0.982} \\
\hline Yes & 17 & 60.7 & 11 & 39.3 & & 15 & 53.6 & 13 & 46.4 & \\
\hline \multicolumn{11}{|l|}{ Methotrexate } \\
\hline No & 13 & 56.5 & 10 & 43.5 & \multirow{2}{*}{0.740} & 12 & 52.2 & 11 & 47.8 & \multirow{2}{*}{0.853} \\
\hline Yes & 23 & 52.3 & 21 & 47.7 & & 24 & 54.5 & 20 & 45.5 & \\
\hline \multicolumn{11}{|l|}{ Prednisolone } \\
\hline No & 21 & 50.0 & 21 & 50.0 & \multirow{2}{*}{0.427} & 19 & 45.2 & 23 & 54.8 & \multirow{2}{*}{0.071} \\
\hline Yes & 15 & 60.0 & 10 & 40.0 & & 17 & 68.0 & 8 & 32.0 & \\
\hline \multicolumn{11}{|l|}{ Biological treatments } \\
\hline No & 19 & 57.6 & 14 & 42.4 & 0524 & 19 & 57.6 & 14 & 42.4 & 0522 \\
\hline Yes & 17 & 50.0 & 17 & 50.0 & 0.534 & 17 & 50.0 & 17 & 50.0 & 0.534 \\
\hline ANA titer & & & & & & & & & & \\
\hline Negative & 22 & 62.9 & 13 & 37.1 & & 17 & 48.6 & 18 & 51.4 & \\
\hline Mild positive & 11 & 50.0 & 11 & 50.0 & 0305 & 13 & 59.1 & 9 & 40.9 & 780 \\
\hline Moderate positive & 2 & 33.3 & 4 & 66.7 & 0.305 & 4 & 66.7 & 2 & 33.3 & 0.788 \\
\hline Strong positive & 1 & 25.0 & 3 & 75.0 & & 2 & 50.0 & 2 & 50.0 & \\
\hline Rheumatoid factor & & & & & & & & & & \\
\hline Negative & 35 & 56.5 & 27 & 43.5 & 01785 & 35 & 56.5 & 27 & 43.5 & 1745 \\
\hline Positive & 1 & 20.0 & 4 & 80.0 & $0.174^{\circ}$ & 1 & 20.0 & 4 & 80.0 & $0.174^{3}$ \\
\hline Uveitis & & & & & & & & & & \\
\hline No & 34 & 56.7 & 26 & 43.3 & $0236^{\S}$ & 33 & 55.0 & 27 & 45.0 & 06965 \\
\hline Yes & 2 & 28.6 & 5 & 71.4 & $0.236^{3}$ & 3 & 42.9 & 4 & 57.1 & $0.696^{3}$ \\
\hline
\end{tabular}

Freq.: frequency, *: statistically significant result ( $<$ 0.005); RF+: positive rheumatoid factor; RF-: negative rheumatoid factor; Exd. Oligarticular: extended olilgarticular; §: significance calculated using Fisher’s exact test. 


\subsection{Predictors for Growth Retardation Severity}

Age at diagnosis and disease duration were analyzed as predictors for growth retardation severity in children with JIA, which was indicated by the number of percentile ranks lost from diagnosis to last follow-up. Regarding height-for-age, severity of growth retardation was predicted by low age at diagnosis and long disease duration in both univariate and multivariate models (Table 4), showing significant correlations with the number of percentile ranks lost from diagnosis to last follow-up (Figure 4(a), Figure 5(a)). Regarding weight-for-age, severity of growth retardation was only predicted by disease duration (Table 4; Figure 4(b) and Figure 5(b)).

\section{Discussion}

\subsection{Epidemiology of Growth Retardation in JIA}

Growth retardation and developmental abnormalities are common complications of JIA and are associated with significant impact on patient's physical and psychological health and overall quality of life [25] [26] [27]. This retrospective study showed high incidence of growth retardation among the local patients. Almost 1 child in 2 had breaks in growth curve, in at least one of the three growth parameters including weight-for-age, height-for-age and weight-forheight. In other studies, pattern of growth varies according to the study population and methodology and to other associated risk factors. Some authors report $10 \%$ to $20 \%$ of growth retardation in children with severe forms of JIA [28], while others reported up to $40 \%$ in all sub-types [21]. A prospective case-control study from India found no significant difference between JIA children and healthy controls. Authors compared weight, height, body mass index and growth velocity over 6 months of children with JIA versus healthy children [29]. This shows relatively high proportion of growth impairment among our study population, which points towards the existence of other probable risk factors.

\subsection{Pathophysiology of Growth Retardation in JIA}

Pathophysiology of growth retardation in children and adolescents with JIA is

Table 4. Predictors for break of the growth curve among children with JIA (ordinal regression).

\begin{tabular}{ccccccccc}
\hline \multirow{2}{*}{$\begin{array}{c}\text { Dependent } \\
\text { variable/predictor }\end{array}$} & \multicolumn{5}{c}{ Univariate model } & \multicolumn{3}{c}{ Multivariate model } \\
\cline { 2 - 8 } & OR & $95 \%$ CI & p-value & OR & $95 \%$ CI & p-value \\
\hline Height & & & & & & & & \\
Age at diagnosis (years) & 1.11 & 1.01 & 1.22 & $0.034^{*}$ & 1.15 & 1.04 & 1.28 & $0.005^{*}$ \\
Disease duration (years) & 0.70 & 0.55 & 0.88 & $0.002^{*}$ & 0.62 & 0.48 & 0.80 & $0.000^{*}$ \\
Weight & & & & & & & & \\
Age at diagnosis (years) & 1.05 & 0.95 & 1.15 & 0.335 & - & - & - & - \\
Disease duration (years) & 0.77 & 0.61 & 0.96 & $0.022^{*}$ & - & - & - & - \\
\hline
\end{tabular}

${ }^{\star}$ Statistically significant result $(\mathrm{p}<0.05)$; OR: odds-ratio; 95\% CI: 95\% confidence interval for OR. 

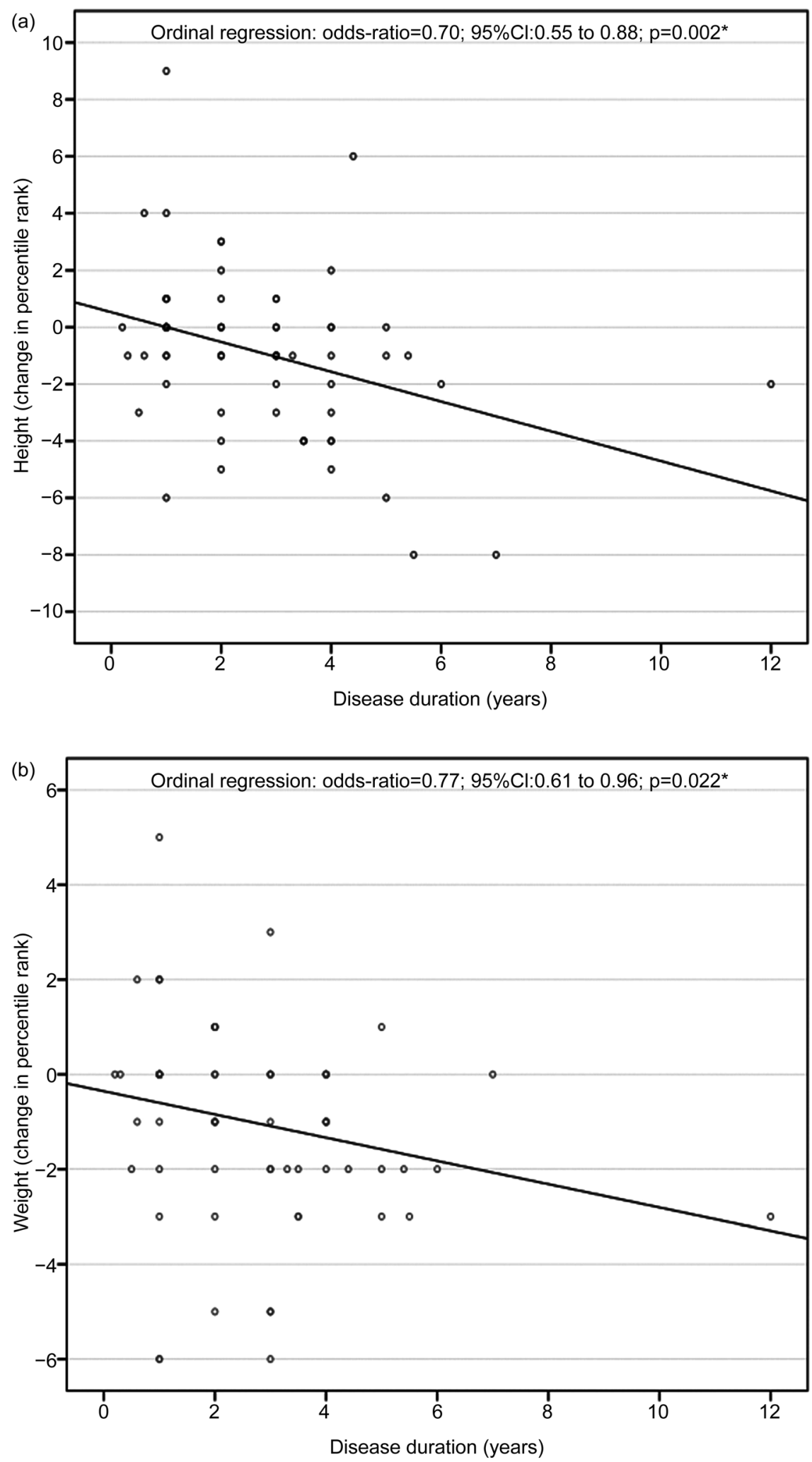

Figure 4. Correlation between disease duration and change in percentile rank for height (a) and weight (b) in children with JIA. Ordinal regression showed that disease duration is a significant risk factor for growth impairment considering both height for age $(\mathrm{OR}=$ 0.70 ; $95 \%$ CI: 0.55 to $0.88 ; \mathrm{p}=0.002^{\star}$; Figure $\left.4(\mathrm{a})\right)$ and weight for age $(\mathrm{OR}=0.77 ; 95 \%$ CI: 0.61 to $0.96 ; \mathrm{p}=0.022^{*}$; Figure $4(\mathrm{~b})$ ). 

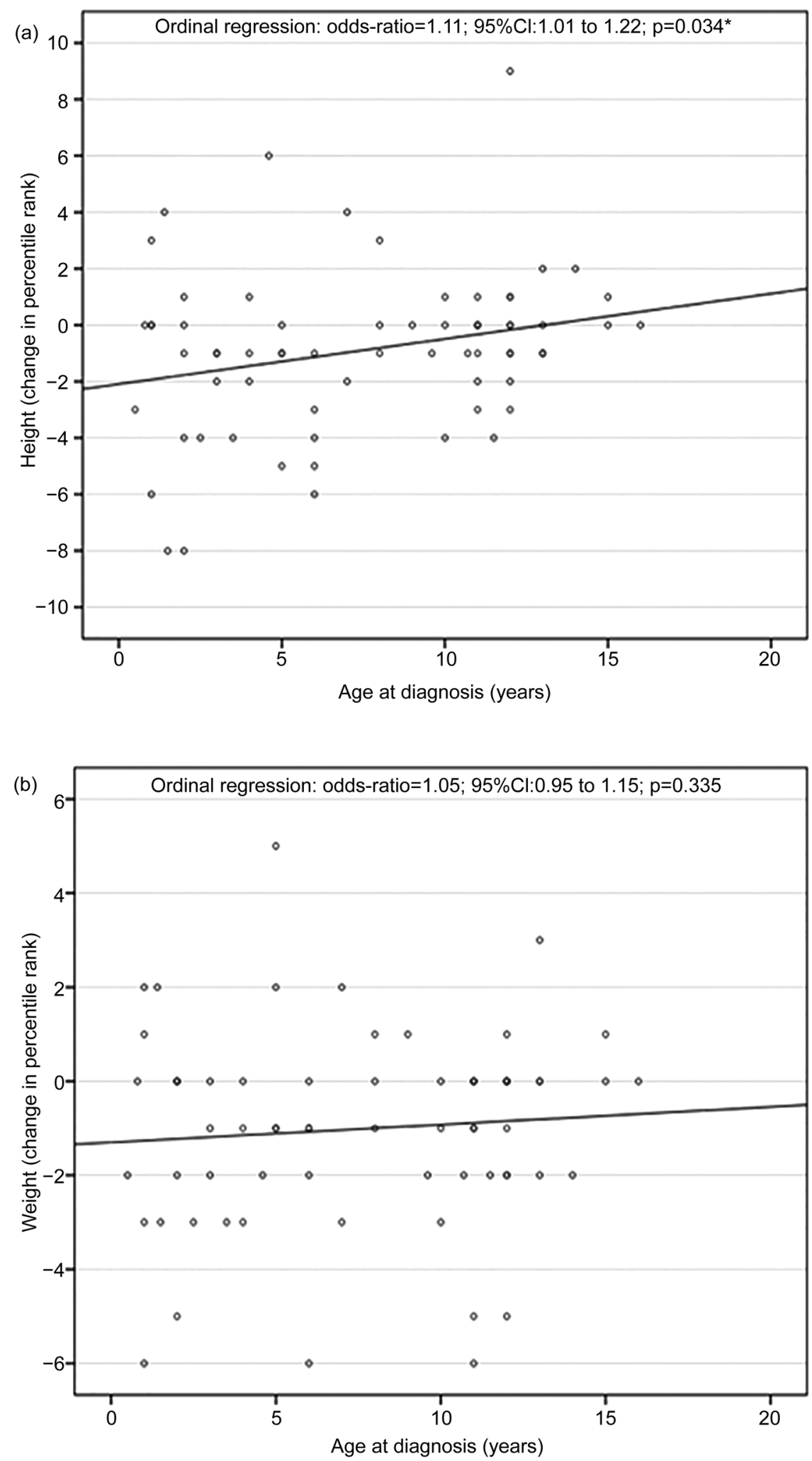

Figure 5. Correlation between age at diagnosis and change in percentile rank for height (a) and weight (b) in children with JIA. Ordinal regression showed that age at diagnosis is a significant predictor for growth impairment, considering height for age $(\mathrm{OR}=1.11$; 95\% CI: 1.01 to $1.22 ; \mathrm{p}=0.0034^{*}$; Figure $\left.5(\mathrm{a})\right)$ but not weight for age (OR $=1.05$; $95 \% \mathrm{CI}$ : 0.95 to $1.15 ; \mathrm{p}=0.335$; Figure $5(\mathrm{~b}))$. 
mainly related to excessive cytokine levels and their pro-inflammatory action; distinctive of severe forms of JIA [30] [31]. There is strong evidence indicating the existence of systemic and local modulating effect of cytokines (especially IL-6) on growth plate of long bones [30] [32] [33]. In addition, cytokines have indirect action involving insulin-like growth factor-I, which was observed to be reduced in serum of patients with systemic JIA and correlated to excessive production of IL-6 [27]. Number of other hormonal and metabolic factors such as parathyroid dysfunction, sex steroids and vitamin D metabolites contribute in growth retardation by modulating growth hormone/insulin-like growth factor-I axis, resulting in impaired bone growth [8]. Growth retardation may also be induced by prolonged use of corticosteroids, especially when initiated in the young age [8] [27]. Other pathophysiological mechanisms include other cytokineinduced epigenetic changes [34] and malnutrition [35].

\subsection{Effect of Age at Diagnosis}

Age at diagnosis and disease duration was the only significant factors correlated with growth retardation. Average age at diagnosis of the population was 7.44 \pm 4.52 years, which was in line with other studies [29] [36] Both the occurrence and severity of height retardation were predicted by the low age at diagnosis of the patient; while the no effect was observed on weight growth. This is generally supported by literature; and may be explained by the level of growth hormone secretion in the childhood, which is physiologically lower than in adolescent, resulting in greater impact of the disease activity (cytokines) on insulin-like growth factors-I secretion in the young; and consequently a delayed long bone growth [8] [37].

\subsection{Effect of Disease Duration}

We demonstrated that disease duration was a significant predictor for the occurrence of growth retardation in both height and weight. In addition, severity of growth retardation, as indicated by the number of percentile ranks lost, was linearly correlated with the number of years of disease duration. In other words, children with long disease duration represent the most frequent and most severe cases of growth retardation among children with JIA. These observations are concordant with data from literature showing greater growth delay in children with long disease duration; which is a common point between all children chronic inflammatory diseases [8] [31] [38].

\subsection{JIA Sub-Types and Growth}

No difference was found between different JIA sub-types in any of the analyzed growth parameters; whereas Mondal et al. reported greater impact on growth velocity in children with polyarticular RF+ form, while children with systemic JIA had the greatest impact on height and weight by comparison to those with other sub-types [29]. Similarly, Okumus et al. reported significantly smaller height in systemic JIA [39]. Severe cases of growth retardation are generally reported in 
polyarticluar forms with multiple joint involvement or systemic forms with extensive damage [21].

\subsection{Effect of Treatments on Growth}

This study demonstrated no significant effect of treatments on growth, be it positive of negative. This may be explained by a relatively short disease duration $(2.93 \pm 2.70$ years), which may be insufficient to observe an effect of treatments. The use of corticosteroids has been demonstrated to induce or exacerbate growth retardation, in a duration- and dose-dependent manner [21]. Furthermore, children treated by corticosteroids in a young age are highly exposed to delayed puberty than those on other treatment regimen [40]. On the other hand, biological therapy, such as anti-TNF- $\alpha$ and anti-IL- 6 have been shown to restore growth, both by reducing disease activity and limiting the use of corticosteroids [41]. Another study demonstrated a strong growth-restoring effect of antiTNF- $\alpha$ in children with polyarticluar JIA, which was correlated to the decrease in disease activity, independently from corticosteroids effect [42]. However, in systemic JIA, growth restoring effect of biologic treatments seems to be less remarkable [43]. Analysis of these observations, among other therapeutic outcomes, justified the current trend of early initiation of aggressive treatment, using several combination of different agents to improve allover disease outcomes including growth [44]. On the other hand, the use of growth hormone has shown good results in restoring growth of JIA patients and should be considered in the management of these patients [45].

None of the other disease-related parameters including ANA, RF and uveitis were significantly associated with growth retardation.

The major limitation of this study was a small sample size, which limited the power of sub-groups analysis; in addition to growth data being missing in number of files, which further reduced the sample size. One other notable limitation was the short follow-up duration of the patients, which prevented from observing significant effects of treatments and other factors on growth. In addition, other growth parameters, such as sexual maturation and bone density were not assessed in this study, both showing to be impaired in JIA in other studies [40] [46].

Despite these limitations, this study provided a sound epidemiological picture of growth retardation among children with JIA and highlighted the importance of systemic and careful assessment of growth parameters in these children.

Future prospective, multicenter studies are warranted to provide a more accurate picture of the growth pattern among JIA children in Saudi Arabia; and investigate further population-specific risk factors associated with this high prevalence. Such study should also assess other parameters including sexual maturation, bone density and local growth abnormalities.

Preventing growth impairment and restoring growth velocity should be among priorities of therapeutic goals. It is achieved through effective decrease of time and severity of disease flare-ups and enhancement of remissions. This requires 
appropriate use of pharmacological treatments along with systemic, close monitoring of physical development and interdisciplinary management involving pediatricians, rheumatologists and clinical anthropologists [21].

\section{Conclusions}

Juvenile idiopathic arthritis is associated with up to $46.1 \%$ cases of growth retardation in Saudi Arabia, which is high by comparison to other studies. Children with young age at diagnosis and long disease duration are at greater risk and represent the most severe cases of growth retardation. The impact of other clinical factors such as JIA sub-types, uveitis and treatments could not be observed; because of the relatively short follow-up and small sample size. Further risk factors for growth retardation in JIA patients should be investigated in this specific population.

Growth is an important, multifactorial complication of JIA that should be detected earlier via systemic and careful assessment, with timely management of further preventable or reversible associated risk factors.

\section{References}

[1] Ravelli, A. and Martini, A (2007) Juvenile Idiopathic Arthritis. The Lancet, 369, 767-778. https://doi.org/10.1016/S0140-6736(07)60363-8

[2] Mcerlane, F., Beresford, M.W., Baildam, E.M., Chieng, S.A., Davidson, J.E., Foster, H.E., Gardner-Medwin, J., Lunt, M., Wedderburn, L.R. and Thomson, W. (2012) Validity of a Three-Variable Juvenile Arthritis Disease Activity Score in Children with New-Onset Juvenile Idiopathic Arthritis. Annals of the Rheumatic Diseases, 72, 1983-1988.

https://www.ncbi.nlm.nih.gov/pubmed/?term=Mcerlane\%2C+F.\%2C+Beresford\%2 C+M.W.\%2C+Baildam\%2C+E.M.\%2C+Chieng\%2C+S.A.\%2C+Davidson\%2C+J.E. $\% 2 \mathrm{C}+$ Foster $\% 2 \mathrm{C}$

[3] Thierry, S., Fautrel, B., Lemelle, I. and Guillemin, F. (2014) Prevalence and Incidence of Juvenile Idiopathic Arthritis: A Systematic Review. Joint Bone Spine, 81, 112 117. https://doi.org/10.1016/j.jbspin.2013.09.003

[4] Moued, M.M., Al-Saggaf, H.M., Habib, H.S. and Muzaffer, M.A. (2013) Oligoarticular Juvenile Idiopathic Arthritis among Saudi Children. Annals of Saudi Medicine, $33,529$.

[5] Hamari, J., Sjöklint, M. and Ukkonen, A. (2015) The Sharing Economy: Why People Participate in Collaborative Consumption. Journal of the Association for Information Science and Technology.

http://people.uta.fi/*kljuham/2015-hamari_at_al-the_sharing_economy.pdf http://onlinelibrary.wiley.com/store/10.1002/asi.23552/asset/asi23552.pdf?v=1\&t=iy qv56gn\&s=e51e0e865fc71fb9fd5864dc6713df05d794fb94

[6] Petty, R.E., Southwood, T.R., Manners, P., Baum, J., Glass, D.N., Goldenberg, J., He, X., Maldonado-Cocco, J., Orozco-Alcala, J. and Prieur, A.-M. (2004) International League of Associations for Rheumatology Classification of Juvenile Idiopathic Arthritis: Second Revision, Edmonton, 2001. The Journal of Rheumatology, 31, 390.

[7] Pan, J., Kapur, M. and McCallum, R. (2014) Noninfectious Immune-Mediated Uveitis and Ocular Inflammation. Current Allergy and Asthma Reports, 14, 1-8. https://doi.org/10.1007/s11882-013-0409-1

[8] Giannini, C., Mohn, A. and Chiarelli, F. (204) Growth Abnormalities in Children 
with Type 1 Diabetes, Juvenile Chronic Arthritis, and Asthma. International Journal of Endocrinology, 2014, Article ID: 265954.

[9] Hashkes, P.J. and Laxer, R.M. (2005) Medical Treatment of Juvenile Idiopathic Arthritis. Journal of the American Medical Association, 294, 1671-1684. https://doi.org/10.1001/jama.294.13.1671

[10] Gowdie, P.J. and Shirley, M. (2012) Juvenile Idiopathic Arthritis. Pediatric Clinics of North America, 59, 301-327. https://doi.org/10.1016/j.pcl.2012.03.014

[11] Dewitt, E.M., Kimura, Y., Beukelman, T., Nigrovic, P.A., Onel, K., Prahalad, S., Schneider, R., Stoll, M.L., Angeles-Han, S. and Milojevic, D. (2012) Consensus Treatment Plans for New-Onset Systemic Juvenile Idiopathic Arthritis. Arthritis Care \& Research, 64, 1001-1010. https://doi.org/10.1002/acr.21625

[12] Gurcay, E., Eksioglu, E., Yuzer, S., Bal, A. and Cakci, A. (2009) Articular Damage in Adults with Juvenile Idiopathic Arthritis. Rheumatology International, 29, 635-640. https://doi.org/10.1007/s00296-008-0740-3

[13] Packham, J. and Hall, M. (2002) Long-Term Follow-Up of 246 Adults with Juvenile Idiopathic Arthritis: Functional Outcome. Rheumatology, 41, 1428-1435. https://doi.org/10.1093/rheumatology/41.12.1428

[14] Kreeftmeijer-Vegter, A.R., de Boer, A., van der Vlugt-Meijer, R.H. and de Vries, P.J. (2014) The Influence of the European Paediatric Regulation on Marketing Authorisation of Orphan Drugs for Children. Orphanet Journal of Rare Diseases, 9, 120. https://doi.org/10.1186/s13023-014-0120-x

[15] Siddique, S.S., Suelves, A.M., Baheti, U. and Foster, C.S. (2013) Glaucoma and Uveitis. Survey of Ophthalmology, 58, 1-10. https://doi.org/10.1016/j.survophthal.2012.04.006

[16] Padeh, S., Pinhas-Hamiel, O., Zimmermann-Sloutskis, D. and Berkun, Y. (2011) Children with Oligoarticular Juvenile Idiopathic Arthritis Are at Considerable Risk for Growth Retardation. The Journal of Pediatrics, 159, 832-837. https://doi.org/10.1016/j.jpeds.2011.04.012

[17] Umławska, W. and Prusek-Dudkiewicz, A. (2006) [Short Stature of Children Suffering from Certain Chronic Diseases]. Pediatric Endocrinology, Diabetes, and Metabolism, 13, 135-138.

[18] Pascual, V., Allantaz, F., Arce, E., Punaro, M. and Banchereau, J. (2005) Role of Interleukin-1 (IL-1) in the Pathogenesis of Systemic Onset Juvenile Idiopathic Arthritis and Clinical Response to IL-1 Blockade. The Journal of Experimental Medicine, 201, 1479-1486. https://doi.org/10.1084/jem.20050473

[19] Bernatsky, S., Duffy, C., Malleson, P., Feldman, D.E., St Pierre, Y. and Clarke, A.E. (2007) Economic Impact of Juvenile Idiopathic Arthritis. Arthritis Care \& Research, 57, 44-48. https://doi.org/10.1002/art.22463

[20] Gaspari, S., Marcovecchio, M.L., Breda, L. and Chiarelli, F. (2011) Growth in Juvenile Idiopathic Arthritis: The Role of Inflammation. Clinical and Experimental Rheumatology, 29, 104-110.

[21] Umławska, W. and Prusek-Dudkiewicz, A. (2010) Growth Retardation and Delayed Puberty in Children and Adolescents with Juvenile Idiopathic Arthritis. Archives of Medical Science, 6, 19-23. https://doi.org/10.5114/aoms.2010.13501

[22] Petty, R.E., Southwood, T., Baum, J., Bhettay, E., Glass, D., Manners, P., Maldonado-Cocco, J., Suarez-Almazor, M., Orozco-Alcala, J. and Prieur, A. (1998) Revision of the Proposed Classification Criteria for Juvenile Idiopathic Arthritis: Durban, 1997. The Journal of Rheumatology, 25, 1991-1994.

[23] Ravelli, A., Magni-Manzoni, S., Pistorio, A., Besana, C., Foti, T., Ruperto, N., Viola, S. and Martini, A. (2005) Preliminary Diagnostic Guidelines for Macrophage Acti- 
vation Syndrome Complicating Systemic Juvenile Idiopathic Arthritis. The Journal of Pediatrics, 146, 598-604. https://doi.org/10.1016/j.jpeds.2004.12.016

[24] El-Mouzan, M.I., Al-Herbish, A.S., Al-Salloum, A.A., Qurachi, M.M. and Al-Omar, A.A. (2007) Growth Charts for Saudi Children and Adolescents. Saudi Medical Journal, 28, 1555-1568.

[25] Simon, D., Fernando, C., Czernichow, P. and Prieur, A.M. (2002) Linear Growth and Final Height in Patients with Systemic Juvenile Idiopathic Arthritis Treated with Long-Term Glucocorticoids. The Journal of Rheumatology, 29, 1296-1300. https://www.ncbi.nlm.nih.gov/pubmed/12064849

[26] Bechtold, S. and Roth, J. (2009) Natural History of Growth and Body Composition in Juvenile Idiopathic Arthritis. Hormone Research in Paediatrics, 72, 13-19. https://doi.org/10.1159/000229758

[27] Murakami, M., Tomiita, M. and Nishimoto, N. (2012) Tocilizumab in the Treatment of Systemic Juvenile Idiopathic Arthritis. Open Access Rheumatology Research and Reviews, 4, 71-79.

[28] Bechtold, S. and Simon, D. (2014) Growth Abnormalities in Children and Adolescents with Juvenile Idiopathic Arthritis. Rheumatology International, 34, 1483 1488. https://doi.org/10.1007/s00296-014-3022-2

[29] Mondal, R., Sarkar, S., Das, N.K., Chakravorti, S., Hazra, A., Sabui, T., Nandi, M., Ray, B., Das, A. and Ganguli, S. (2014) Growth of Children with Juvenile Idiopathic Arthritis. Indian Pediatrics, 51, 199-202. https://doi.org/10.1007/s13312-014-0383-2

[30] MacRae, V., Wong, S., Farquharson, C. and Ahmed, S. (2006) Cytokine Actions in Growth Disorders Associated with Pediatric Chronic Inflammatory Diseases. International Journal of Molecular Medicine, 18, 1011-1018. https://doi.org/10.3892/ijmm.18.6.1011

[31] Simon, D. (2010) Inflammation and Growth. Journal of Pediatric Gastroenterology and Nutrition, 51, S133-S134. https://doi.org/10.1097/mpg.0b013e3181f7feef

[32] MacRae, V., Farquharson, C. and Ahmed, S. (2006) The Restricted Potential for Recovery of Growth Plate Chondrogenesis and Longitudinal Bone Growth Following Exposure to Pro-Inflammatory Cytokines. Journal of Endocrinology, 189, 319-328. https://doi.org/10.1677/joe.1.06609

[33] Nakajima, S., Naruto, T., Miyamae, T., Imagawa, T., Mori, M., Nishimaki, S. and Yokota, S. (2009) Interleukin-6 Inhibits Early Differentiation of ATDC5 Chondrogenic Progenitor Cells. Cytokine, 47, 91-97.

https://doi.org/10.1016/j.cyto.2009.05.002

[34] MacRae, V., Farquharson, C. and Ahmed, S. (2006) The Pathophysiology of the Growth Plate in Juvenile Idiopathic Arthritis. Rheumatology, 45, 11-19. https://doi.org/10.1093/rheumatology/kei091

[35] Cleary, A., Lancaster, G., Annan, F., Sills, J. and Davidson, J. (2004) Nutritional Impairment in Juvenile Idiopathic Arthritis. Rheumatology, 43, 1569-1573. https://doi.org/10.1093/rheumatology/keh387

[36] Lotfy, H.M., Street, A.O. and Mohandessen, C. (2009) Juvenile Idiopathic Arthritis, the Egyptian Experience. Journal of Medical Sciences, 9, 98-102. https://doi.org/10.3923/jms.2009.98.102

[37] Wit, J.M. and Camacho-Hübner, C. (2011) Endocrine Regulation of Longitudinal Bone Growth. In: Camacho-Hübner, C., Nilsson, O. and Sävendahl, L., Eds., Cartilage and Bone Development and Its Disorders, Vol. 21, Karger Publishers, Basel, 30 41. https://doi.org/10.1159/000328119

[38] Liem, J. and Rosenberg, A. (2002) Growth Patterns in Juvenile Rheumatoid Arthritis. Clinical and Experimental Rheumatology, 21, 663-668. 
[39] Okumus, O., Erguven, M., Deveci, M., Yilmaz, O. and Okumus, M. (2008) Growth and Bone Mineralization in Patients with Juvenile Idiopathic Arthritis. The Indian Journal of Pediatrics, 75, 239-243. https://doi.org/10.1007/s12098-008-0052-3

[40] El Badri, D., Rostom, S., Bouaddi, I., Hassani, A., Chkirate, B., Amine, B. and Hajjaj-Hassouni, N. (2014) Sexual Maturation in Moroccan Patients with Juvenile Idiopathic Arthritis. Rheumatology International, 34, 665-668. https://doi.org/10.1007/s00296-013-2737-9

[41] Świdrowska, J., Zygmunt, A., Biernacka-Zielińska, M., Stańczyk, J. and Smolewska, E. (2015) Influence of Biologic Therapy on Growth in Children with Chronic Inflammatory Connective Tissue Diseases. Reumatologia, 53, 14-20. https://doi.org/10.5114/reum.2015.50552

[42] Tynjälä, P., Lahdenne, P., Vähäsalo, P., Kautiainen, H. and Honkanen, V. (2006) Impact of Anti-TNF Treatment on Growth in Severe Juvenile Idiopathic Arthritis. Annals of the Rheumatic Diseases, 65, 1044-1049. https://doi.org/10.1136/ard.2005.047225

[43] Uettwiller, F., Perlbarg, J., Pinto, G., Bader-Meunier, B., Mouy, R., Compeyrot-Lacassagne, S., Melki, I., Wouters, C., Prieur, A.-M. and Landais, P. (2014) Effect of Biologic Treatments on Growth in Children with Juvenile Idiopathic Arthritis. The Journal of rheumatology, 41, 128-135. https://doi.org/10.3899/jrheum.130311

[44] Consolaro, A., Giancane, G., Schiappapietra, B., Davì, S., Calandra, S., Lanni, S. and Ravelli, A. (2016) Clinical Outcome Measures in Juvenile Idiopathic Arthritis. Pediatric Rheumatology Online Journal, 14, 23. https://doi.org/10.1186/s12969-016-0085-5

[45] Bechtold, S., Ripperger, P., Pozza, R.D., Roth, J., Häfner, R., Michels, H. and Schwarz, H.P. (2010) Dynamics of Body Composition and Bone in Patients with Juvenile Idiopathic Arthritis Treated with Growth Hormone. The Journal of Clinical Endocrinology \& Metabolism, 95, 178-185. https://doi.org/10.1210/jc.2009-0979

[46] Garcia-Consuegra, M.J., Merino, M.R., Lama, M.R., et al. (2003) Growth in Children with Juvenile Idiopathic Arthritis. Anales de Pediatria (Barcelona), 58, 529-537. https://www.ncbi.nlm.nih.gov/pubmed/?term=Garcia-Consuegra+Molina+J\%2C+ $\underline{\mathrm{Me}-}$ $\underline{\text { ri-no+Munoz }+\mathrm{R} \% 2 \mathrm{C}+\mathrm{Lama}+\text { More }+\mathrm{R}+\mathrm{et}+\mathrm{al} .+ \text { Growth }+\mathrm{in}+\text { children+with +juvenile }}$ +idiopathic+arthritis

Submit or recommend next manuscript to SCIRP and we will provide best service for you:

Accepting pre-submission inquiries through Email, Facebook, LinkedIn, Twitter, etc. A wide selection of journals (inclusive of 9 subjects, more than 200 journals)

Providing 24-hour high-quality service

User-friendly online submission system

Fair and swift peer-review system

Efficient typesetting and proofreading procedure

Display of the result of downloads and visits, as well as the number of cited articles

Maximum dissemination of your research work

Submit your manuscript at: http://papersubmission.scirp.org/

Or contact ojra@scirp.org 